\title{
Covid-19 Challenges and What Augmented Reality Offers in Solution
}

\author{
Nevzat Unalan \\ Ufuk University, Vocational School, Ankara / Turkey \\ E-mail: nevzat.unalan@ufuk.edu.tr, \\ 0000-0002-7489-2852
}

\begin{abstract}
Aim: The aim of this study is to reveal what kinds of technologies, tools and working methods are needed to solve the problems while the impact of the coronavirus is hurting people and businesses and to reveal the benefits and importance of the use of the augmented reality technology in overcoming COVID-19 challenges.

Methods: In this study, a survey consisting of structured questions prepared by GlobalWebIndex, which includes user expectations and problems in the use of internet, social media, mobile devices and ecommerce, was used.

Results: While the impact of the coronavirus harms people and businesses, it is obvious that just new emerging technologies can be used to solve this problem. It is clear that there is a need for newly developed tools and working methods to overcome such challenges. Restrictions imposed by Governments have led to an increase in the use of digital technologies such as online shopping, digital and contactless payments, remote work, online education, telehealth and entertainment. The ability of societies to support these activities may vary largely due to the availability of "digitally available" infrastructure and services. In this way, societies with developed infrastructure are less affected by the effects of the pandemic and can ensure business continuity, and societies with insufficient information system infrastructure experience deep gaps in the continuation of social activities.

Conclusion: Obviously, new or improved tools and ways of working are needed to help tackle these challenges. The emerging new technologies have created augmented reality technology by adding layers of digital information such as sound, video and graphics on the appearance of the physical world by affecting the changing living conditions. One of the solutions that can help reduce the social and commercial impact of the pandemic and support business continuity is Augmented Reality (AR), which is defined as a remote assistance area.
\end{abstract}

Keywords: Augmented Reality, Challenges, Epidemic, COVID-19

DOI: $10.7176 / \mathrm{JSTR} / 7-03-01$

\section{Introduction}

When the Covid-19 epidemic began to spread inexorably in the world and Turkey, all countries suddenly became its epicenter. Societies experiencing this epidemic divided their lives into two parts as Pre-Coronavirus and Post-Coronavirus. Some existential threats such as Covid-19 have the power to reshape human societies. It is too early to say how little or how much this pandemic will reshape community life, but it will do so in many ways that are not yet understood. As we move to a "new normal" and beyond, this crisis seems inevitable to have a likely impact that continues in the coming months. Currently, social distancing measures limit the size of groups that can be convened with traditional face-to-face interaction. Travel restrictions and curfew affect negatively shopping, banking, work, education, health and entertainment. Companies are obliged to use less labor force due to isolation and budget constraints, and they are prevented from continuing their activities as usual. It is clear that new or improved tools and new working methods are needed to overcome these challenges.

1 | P a g e www.iiste.org 
One of the solutions that can help reduce the social and commercial impact of the pandemic and support business continuity is Augmented Reality (AR), which is defined as a remote assistance area. In the first year of the Covid-19 outbreak, the society, scientists and states continue to work hard to control the disease and cope with the problem. It is said that social distance and masking is the best solution besides medical solutions. It is also stated that mapping is necessary in order to apply largescale social distance. As these efforts now move to a "new normal" and beyond, it seems inevitable that this crisis will have a possible impact that will continue in the coming months. Currently, social distancing measures limit the size of groups that can be brought together through traditional face-toface interaction. In addition, restrictions imposed by governments have led to an increase in the use of digital technologies such as online shopping, digital and contactless payments, remote work, online education, telehealth and entertainment (McKinsey \& Company, 2020).

The global pandemic can pose another problem when daily activities involving economic or educational activities require social proximity. This means the infection is increasing. At this point, there are scientific minorities that can lead to weaknesses. Unfortunately, societies have difficulty in developing measures such as wearing masks and using more effective disinfectant and filtering systems in public transport. All of this points to fundamental challenges even with vaccines, testing and mapping, which means infections will continue. (Ferguson et al., 2020)

It is clear that new or improved tools and new working methods are needed to overcome these challenges. The aim of this study is to reveal the benefits and importance of the use of the augmented reality technology in overcoming COVID-19 challenges. Within the scope of this main purpose, the article will answer the following sub-objectives:

What are the COVID-19 Challenges encountered to date?

What does Augmented Reality offer to solve COVID-19 problems?

What are the future technological approaches in the fight against Covid-19?

\section{Research Method}

A questionnaire, prepared by GlobalWebIndex, consisting of structured questions was applied to the staff in order to determine user expectations and problems in using the internet, social media, mobile devices, and ecommerce. A quantitative method was used to determine the validity and reliability of the questionnaire in order to evaluate the aspects of using the internet, social media, mobile devices, and ecommerce.

\subsection{Evaluation of Demographic Features}

It consists of personal information such as gender, age, education level, income level, internet connection preference and social network usage.

\subsection{Collection of Data}

As a data collection tool, the questionnaire technique prepared by GlobalWebIndex, which is made by preparing a list of questions that will be read and answered directly by the people to be informed, was used.

\subsection{Scale of the Study}

Likert type scale was used in the study, and they were ranked from very negative to very positive in order to determine the opinions of the individuals about the given propositions.

\subsection{Research Universe}

Figures represent the findings of a survey of internet users aged 16 to 64 whom applied to millions of participants in Germany, Italy, Spain, France, The United Kingdom, Ireland from Europe, The United States, Brazil, Canada form America, China, Japan, India, New Zealand, Philippines, Singapore and Australia from far East. Data collection took place between March 31 and April 02, 2020 by Digital 2020 April Global Statshot Report.

\section{COVID-19 Challenges}

\subsection{Stand-Off Detection}

The pandemic of SARS-CoV-2 emphasizes that the health workers are in need of stand-off technologies. The current diagnostic methods of viral pathogens are nucleic acid amplification tests, serological assays and cell culture-based methods. All of these methods require contact to patient and

2| P a g e www.iiste.org 
patient's samples. Laser-based technologies are widely studied in this aspect of field. COVID-19 is transmitted via droplets, the detection of respiratory viral droplets in the air that the patient gives breath with ultraviolet laser induced florescence will be a revolutionary step in diagnostics. This will effectively minimize the risk of transmission to healthcare professionals during diagnosis.

Most of the countries are in need for this kind of medical instruments, since importation of these caused a crisis worldwide. In the post-COVID-19 era, countries should support national production of this medical instruments.

\subsection{Improved Situational Awareness}

One of the clearest trends in the pandemic days has been a dramatic increase in socializing through digital platforms, whether with family, friends or social groups. According to the data of GlobalWebIndex, 47 percent of internet users stated that they used social media longer in pandemic conditions, while the number of these users increased by 23 percent. As a result of isolation measures, restraints and total lockdown, people have created more opportunities to communicate with the outside world through digital platforms.

\begin{tabular}{|l|c|}
\hline Activity & Increase Percentage \\
\hline Watching more news coverage & $\% 35$ \\
\hline Watching more films on streaming services & $\% 29$ \\
\hline Spending more time using messenger services & $\% 24$ \\
\hline Spending more time using social media & $\% 23$ \\
\hline Watching more TV on broadcast television channels & $\% 19$ \\
\hline
\end{tabular}

Source: https://wearesocial-net.s3.amazonaws.com/uk/wp-content/uploads/sites/2/2020/04/07-Significant-Changes-in-MediaHabits-DataReportal-20200422-Digital-2020-April-Global-Statshot-Report-Slide-13.png

For the improved situational awareness, social media should be used wisely. These platforms are the easiest and fastest way of communication and the spread of information. However, spread of misinformation (for example, 180 death in Iran from toxic alcohol) is the most dangerous handicap of these platforms. Worldwide and country-based strategies should be put in order to prevent the spread of harmful misinformation.

\subsection{Moral Injury}

The reported statistics reveal that the number of violent actions within the community are also increasing. What is more dangerous than the contagion is the panic and anxiety it causes. Moral injury, the profound psychological distress associated with perpetrating or witnessing acts that violates a person's fundamental moral beliefs, is very relevant to consider in the context of COVID-19. Indeed, there is a potential for moral injury whenever a person wishes to act but is prevented from doing so, must respond with inadequate resources, makes difficult decisions between the treatment of vulnerable people, and between their own, own family, and others safety or survival. Moral injury can also ensue when people feel that their own survival, safety, and wellness are not being adequately provided for by those responsible for managing them within a work context. During the COVID-19 pandemic many key workers are being exposed to morally challenging situations; not just health workers but a much wider range of key workers including social workers, delivery drivers and others who have to work differently and make unusual decisions.

For all of these reasons we would expect that moral injury could affect a wide range of people and various occupations. In addition, moral issues may well be triggered by national decisions to 'reopen' which may be done prematurely or in other ways that betrays public trust, is not based on scientific advice and by relying on testing or digital tools, e.g., tracking apps, which may not be scientifically sound.

\subsection{Decontamination}

Decontamination of surfaces is an easy but effective way of controlling the spread of SARS-CoV-2. On the other hand, given the short supply of resources, it should be used cost-effectively. Also, it should be kept in mind that the disinfectants are biohazardous materials so the senseless and excessive use can cause more harm than the virus itself.

3 | P a g e

www.iiste.org 


\section{A Solution to COVID-19 Challenges; Augmented Reality}

As we move to a "new normal" and beyond, this crisis seems inevitable to have a likely impact that continues in the coming months. Currently, social distancing measures limit the size of groups that can be convened with traditional face-to-face interaction. Travel restrictions and the inability of key service personnel affect negatively local expertise when needed. The use of fewer on-site staff due to illness, self-isolation, and financial constraints impede companies' ability to continue their operations as before. Disrupted supply chains require more flexible production and sourcing processes to help ensure continuity of production. The potential for virus transmission causes reluctance among employees to touch surfaces and objects that may have been touched by others. However, people started spending more time using laptops and mobile devices to find ways to cope with these challenges.

\begin{tabular}{|l|c|}
\hline People spending more times with devices & Percentage Increase \\
\hline Smartphones or mobile phones & $\% 76$ \\
\hline Laptop Computer & $\% 45$ \\
\hline Desktop Computer & $\% 32$ \\
\hline Table Device & $\% 22$ \\
\hline Smart TV or Media Streaming Device & $\% 34$ \\
\hline
\end{tabular}

Source: https://wearesocial-net.s3.amazonaws.com/uk/wp-content/uploads/sites/2/2020/04/03-Device-Time-Increase-OverallDataReportal-20200422-Digital-2020-April-Global-Statshot-Report-Slide-9.png

Along with these, restrictions imposed by Governments have led to an increase in the use of digital technologies such as online shopping, digital and contactless payments, remote work, online education, telehealth and entertainment. The ability of societies to support these activities may vary largely due to the availability of "digitally available" infrastructure and services. In this way, societies with developed infrastructure are less affected by the effects of the pandemic and can ensure business continuity, and societies with insufficient information system infrastructure experience deep gaps in the continuation of social activities.

Obviously, new or improved tools and ways of working are needed to help tackle these challenges. The emerging new technologies have created augmented reality technology by adding layers of digital information such as sound, video and graphics on the appearance of the physical world by affecting the changing living conditions (Kipper ve Rampolla, 2012). One of the solutions that can help reduce the social and commercial impact of the pandemic and support business continuity is Augmented Reality (AR), which is defined as a remote assistance area. Remote assistance enhanced with AR provides a lively video sharing experience between two or more people. AR is a system that provides a live view of a physical, real-world environment augmented by computer-generated input such as information, audio, video, graphics or GPS data. (Akram and Kumar, 2017: 168; Bilici, 2015: 30). AR, is the reality environment where digital media products are used instead of real-world objects (Milgram and Kishino 1994). AR is a virtual technology based on interaction, which is the result of integrating real-time and real-life conditions with each other (Azuma 1997). AR is a new technology that can be used in various fields such as education, medicine, game industry, military applications, sports, health and has attracted great interest in recent years.

\subsection{Remote Assistance}

The COVID-19 pandemic has had an unprecedented impact on the global business environment. With the pandemic, various forms of segregation have been put in place by many countries, severely limiting the way companies do business and halting operations in many cases.

Companies strive to maintain business continuity despite this new normal, curfew restrictions and social distancing measures. Difficulties of employees in the primary phase such as going to malfunction, providing maintenance and repair of machines are overcome with AR. With this type of application, a highly effective cooperation is achieved, for example between a customer with a faulty machine and a remote specialist working from home. AR combines the physical and digital worlds with remote assistance, enabling communities to digitally open up to the physical world around them by providing communication and collaboration between employees and customers. When equipment or product front-line workers cannot solve technical problems personally, they connect with expert systems using remote assistance developed with AR, providing fast resolution of problems with contextual information and expert guidance. This new normal helps mitigate the effects of curfews, reduced staffing and of course social distancing.

4 | P a g e

www.iiste.org 


\subsection{Remote non-touch product interaction}

AR skills have different virtual interfaces that will make it easier for many employees to perform their jobs. For example, there are many types of medical practitioners that can help them fulfill their duties during the current pandemic and beyond. While helping to reduce the amount of physical contact between the doctor and the patient, there are some practices that also allow them to communicate with colleagues outside the COVID-19 treatment area. While a doctor wearing a Mixed Reality Headgear can interact using hand gestures with medical contents such as X-rays, scans, test results, other medical staff can attend the consultation from a safe distance. Today, devices and applications are controlled hands-free, movement or sound is used to tell the device what to do, and it is turned on and off by making changes on the device with sound. Patient examination and viewing of results are performed without touching any device.

AR quickly provides interactive training methods to teach medical professionals new medical equipment and different medical procedures, when there are no experienced personnel and new personnel need to be trained as soon as possible.

Such applications of AR significantly reduce the risk of human error, significantly shorten training periods, provide hygienic working environments for employees, reduce the need for Personal Protective Equipment (PPE), and reduce the amount of touch required by physical objects that can be used by a large number of people by providing abstract interactions. offers.

\subsection{Remote Collaboration and Education}

AR enables physically separated users to sit in a virtual space shared by the AR application. With this ability, real-time images and discourses of all participants who can position themselves in their physical space can be presented. Users can provide visual feedback and verbal explanation to the shared environment.

AR is used as an effective educational material at all levels from primary education to university by providing enriched environments by integrating virtual objects into world environments (Ozdemir, 2017). At the primary education level, students are enabled to participate actively in in-class activities, they allow students to interact with each other, and lessons are made fun by creating the feeling of playing games. It is used as an effective tool in teaching abstract concepts by creating a sense of reality with the effect of the presented 3D visualization. In higher education, the design of an electronic system in an engineering course, the introduction of the human body or an organ is explained more effectively with the application developed in a medical school course. Images, models, animations and textual information belonging to different layers such as human anatomy, muscle, skeleton, nervous systems and tissues are presented.

While solutions such as video conferencing and live lectures solve the need to bring people together, real-time access brings together 3D data, which is essential for both people and effective collaboration and business continuity. These abilities of AR play a key role in alleviating the restrictions on social distance and the proximity of human-human interaction, the inability of groups to come together due to curfews and restrictions (Dunleavy and Dede, 2014).

\subsection{Remote sales activities}

The trend towards e-commerce increased all over the world in the period of lockdown. According to GlobalWebIndex data at the beginning of April 2020, when the crisis broke out, almost half of internet users stated that they were shopping online. As a result of the COVID-19 isolation in their countries, a third of internet users have made more purchases online for these items.

\begin{tabular}{|l|c|}
\hline Increase in Ecommerce Interest by Item & Percentage Increase \\
\hline Food Groceries & $\% 33$ \\
\hline Household Essentials & $\% 29$ \\
\hline Personal Care Products & $\% 27$ \\
\hline Clothes & $\% 19$ \\
\hline Entertainment Items & $\% 17$ \\
\hline Cosmetics and Beauty Products & $\% 17$ \\
\hline
\end{tabular}

Source: https://wearesocial-net.s3.amazonaws.com/uk/wp-content/uploads/sites/2/2020/04/41-Ecommerce-Interest-byCategory-DataReportal-20200422-Digital-2020-April-Global-Statshot-Report-Slide-113.png

5 | P a g e

www.iiste.org 
Interest in e-commerce has seen the greatest increase in the food and supermarket category. Visits to supermarket websites increased by 251 percent between 8-15 April 2020.

\begin{tabular}{|l|c|}
\hline Impact on Ecommerce WEB Traffic & Percentage Increase \\
\hline Supermarkets & $\% 251$ \\
\hline Retail Tech & $\% 78$ \\
\hline Media & $\% 56$ \\
\hline Telecom & $\% 29$ \\
\hline Home Furnishing & $\% 19$ \\
\hline Retail Healthcare & $\% 13$ \\
\hline
\end{tabular}

Source: https://wearesocial-net.s3.amazonaws.com/uk/wp-content/uploads/sites/2/2020/04/42-Ecommerce-Website-TrafficChange-DataReportal-20200422-Digital-2020-April-Global-Statshot-Report-Slide-114.png

AR has also been an effective sales tool that keeps sales processes going during the pandemic. The use of interactive sales demonstrations facilitated by AR allows the buyer to understand the shape, fit and function of a product without the need to travel, touch, or interact with a salesperson. For example, a 1: 1 scale vehicle design can be examined remotely, and detailed information about a household item to be purchased can be obtained. Those who shop goods for the home can get feedback by examining the digital presentations of the items or furniture placed in their physical spaces. AR enables buyers to place and interact with products in their physical environment by enhancing the remote shopping experience.

\section{Conclusion}

Nowadays, people do not want to give up face-to-face meetings, shopping in the centers, meals in restaurants, tourism and travelling. Especially by the education and business world, it is trying to find solutions to return to the old normal and start working again safely. But it is not yet known how the whole world will come out of the Covid-19 shock and whether the emerging new technologies will be a part of the solution.

While the impact of the coronavirus harms people and businesses, it is obvious that just new emerging technologies can be used to solve this problem. It is clear that there is a need for newly developed tools and working methods to overcome such challenges. Restrictions imposed by Governments have led to an increase in the use of digital technologies such as online shopping, digital and contactless payments, remote work, online education, telehealth and entertainment. The ability of societies to support these activities may vary largely due to the availability of "digitally available" infrastructure and services. In this way, societies with developed infrastructure are less affected by the effects of the pandemic and can ensure business continuity, and societies with insufficient information system infrastructure experience deep gaps in the continuation of social activities.

Obviously, new or improved tools and ways of working are needed to help tackle these challenges. The emerging new technologies have created augmented reality technology by adding layers of digital information such as sound, video and graphics on the appearance of the physical world by affecting the changing living conditions. One of the solutions that can help reduce the social and commercial impact of the pandemic and support business continuity is augmented reality, which is defined as a remote assistance area. Augmented Reality can serve many purposes for remote working, training, selling products and services, ensuring the continuity of the economic system. AR is the technology that will lead the "new normal" habits that will be experienced in the world after covid-19. It is likely that after Covid-19, the entry of augmented reality into our lives will be as fast as mobile phones and computers and will take place in our lives more than ever.

\section{References}

Akram, W. and Kumar, R. (2017). A study on role and applications of augmented reality in tourism: its challenges and future prospects, International Journal of Advanced Research in Computer Science, 8 (8): 168-172.

Azuma, R. T. (1997). A survey of augmented reality. Presence: Teleoperators \& Virtual Environments, 6(4), 355-385

6| P a g e

www.iiste.org 
Bilici, F. (2015). Pazarlamada Artırılmış Gerçeklik ve Kare kod Teknolojileri: Tüketicilerin Artırılmış Gerçeklik Teknoloji Algılamaları Üzerine Bir Alan Araştırması, (Yayımlanmış Yüksek Lisans Tezi), Uludağ Üniversitesi Sosyal Bilimler Enstitüsü, Bursa

Dunleavy, M., \& Dede, C. (2014). Augmented reality teaching and learning. In Handbook of research on educational communications and technology (pp. 735-745). Springer, New York, NY.

Ferguson, N. et al. (2020), Impact of non-pharmaceutical interventions (NPIs) to reduce COVID-19 mortality and healthcare demand, http://dx.doi.org/10.25561/77482.

GlobalWebIndex Coronavirus Multimarket Study, April 2020

Kipper, G., \& Rampolla, J. (2012). Augmented Reality: an emerging technologies guide to AR. Elsevier.

McKinsey \& Company, (2020) The Next Normal Digitizing at speed and scale the recovery will be Digital, 22-23

Milgram, P., \& Kishino, F. (1994). A taxonomy of mixed reality visual displays. IEICE TRANSACTIONS on Information and Systems, 77(12), 1321- 1329.

Ozdemir, M. (2017). Educational Augmented Reality (AR) Applications and Development Process. In Mobile Technologies and Augmented Reality in Open Education, 26-53, IGI Global. 